\title{
Web-Based Application of Fuzzy Inference System to Diagnose Disease
}

\author{
Chairisni Lubis ${ }^{1}$, Agus Budi Dharmawan ${ }^{2}$, Ery Dewayani ${ }^{3}$, Novario Jaya Perdana ${ }^{4}$, Yosua \\ Andre Setiawan ${ }^{5}$ \\ $\left\{\right.$ chairisnil@fti.untar.ac.id ${ }^{1}$ \}
}

Fakultas Teknologi Informasi, Universitas Tarumanagara

\begin{abstract}
In Artificial Intelligence, Fuzzy Theory has the ability to solve the problem of uncertainty in a data. In expert systems, the problem of data uncertainty in the form of facts in the acquisition of knowledge becomes very important if you want to produce a solution. In diagnosing diseases, a data collection is used to help experts determine the disease suffered by patients. Difficulties are found when data analyzed by an expert system has many slices between one disease and another. Therefore to increase the level of success of expert systems for diagnosing diseases, Fuzzy theory is used to represent the level of symptoms of the disease. So that the Application Program designed can be used by many users, the Application Program is designed based on the Web. In the testing phase of the Fuzzy Inference System application to diagnose this disease it can be concluded that the functions in each module and button in this application program have functioned according to the design that has been made.
\end{abstract}

Keywords: disease, fuzzy inference system, fuzzy theory.

\section{Introduction}

Information about an illness is very important, especially in the world of health, because it is useful for making decisions in diagnosing or treating an illness. Processing the information must be done properly and correctly. In the medical world, prospective doctors and experts need an adequate Information Technology container to be used in diagnosing a disease in the form of media that can store data in a structured manner or a container to store information about a disease systematically. For this reason, it is necessary to make an information technology application about a disease that can be used by medical experts and prospective doctors and is not limited by space and time. In this application there is a function of classifying disease categories based on symptoms experienced.

Applications like this are usually desktop-based applications. However, along with its development, desktop-based applications have started to be abandoned because they are considered to be less flexible, less secure, difficult to update, and cost too much. So, web-based applications are a solution to overcome various problems that are often present when using desktop-based applications. One of the advantages of using a web-based application is that when doing an update on data, it is enough to do it on the server, so the data can automatically be integrated into other computers.

Fuzzy Inference System also called Fuzzy Inference System (FIS) is a system that can do reasoning with the same principle as humans do reasoning with their instincts. [1] Fuzzy 
inference systems have been successfully applied in fields such as automatic control, data classification, decision analysis, expert system, and computer vision. Because of the multidisciplinary nature, fuzzy inference systems are associated with a number of names such as fuzzy modeling, fuzzy expert systems, fuzzy controller logic, associative fuzzy memory, and only fuzzy systems[1][2].

In fuzzy inference systems there are several types of methods that can be used, namely Tsukamoto, Mamdani, and Sugeno[3][2]. In designing this application the method that will be used is the Sugeno method. The Sugeno method is used because it is simpler to apply in this case. This method is a fuzzy inference method for rules that is represented in the form of IF THEN which outputs (consequent) systems are not in the form of fuzzy sets but rather are constants or linear equations. For the reasoning process the method used is Forward Chaining which traces each evidence to produce a conclusion.

The benefit of using fuzzy logic in this application is to diagnose the disease and determine the severity of a symptom and disease. Through these applications, doctors are expected to be able to use them. Now doctors can use this application as a medium to store data on various diseases, make it easy to explain to patients about their illness and the severity of their illness using data that is well organized. In addition, it also makes it easier for doctors to make decisions in diagnosing and treating patients.

Based on the background description of the problem above, a knowledge base for the system is needed in the form of a database of symptoms and diseases which will then form a rule which is then collected and described in a systematic design form. Fuzzy variables are linguistic variables of symptoms. The design of this fuzzy inference system application is made using the ASP.NET programming language. The database used is SQL Server Management Studio 2014.

The approach of the fuzzy inference system method used for decision making is to use the Fuzzy Sugeno method[3]. While the reasoning method used in the design is Forward Chaining which starts with the existing information and merges rules to produce a conclusion or goal of the problem at hand. The design of this system is for doctors. Based on the symptoms given the program can make inferences so that it can produce a diagnosis of the disease suffered by the patient.

The purpose of making this application is to get a more accurate diagnosis of the disease, where the use of the fuzzy inference system method is able to provide the results of the diagnosis and the severity of the disease suffered by the patient.

This application can also be used for doctors in making decisions. This is done by diagnosing the symptoms suffered by the patients then the patient's symptoms are inputted into the program of fuzzy inference systems, so as to produce the results of the diagnosis and the level of accuracy. These results are then used to take the hypothesis of the disease suffered by the patient.

The difference in the design of this fuzzy inference system application with the design of the expert system before is in addition to diagnosing the disease this application can also determine the severity of the possibility of the disease suffered by the patient.

\section{Discussion}

The application program designed is an application to diagnose several types of diseases and also determine the severity of the disease. The design method used is the Expert System 
Development Life Cycle (ESDLC) method because with this method the design becomes structured starting from the problem identification process, determining the knowledge base to its actual application.

In this application the design concept and design of the fuzzy inference system used is an application based on the Rule Based Expert System which is used to diagnose several diseases. Disease diagnosis is based on user-selected clinical symptoms from a list of symptoms that have been entered in the database. This application applies the Fuzzy Sugeno method by using triangular and trapezoidal membership functions to get the severity of the possible diseases produced. The inference engine in this application program uses Forward Chaining reasoning which starts from the available information in the form of symptoms, then conclusions are drawn in the form of diagnosis of the disease and the severity of each disease. There are five stages of fuzzy inference system, namely, fuzzyfication, fuzzy logic operations, implications, aggregation, defuzzyfication. The block diagram of the stages of the fuzzy inference system can be seen in Figure 1.

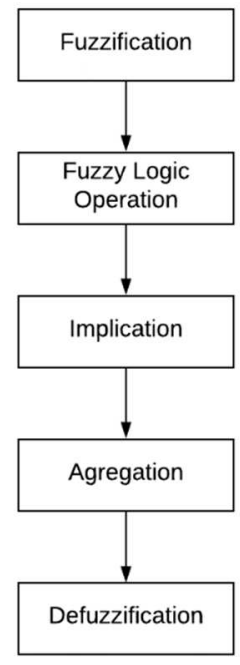

Fig. 1. FIS Block Diagram

In the application fuzzyfication stage, membership functions are used. The membership function is a curve that shows the mapping of input data points into its membership value. [4] Fuzzy membership functions are divided into five, namely, linear membership functions consisting of linear ascending and linear descending, triangle membership functions, trapezoidal membership functions, membership functions of the sigmoid curve consisting of growth curves and depreciation curves, and bell curve membership functions. In this application, the membership function used is only two, namely triangular and trapezoidal functions. The following is a formula for triangular and trapezoidal functions:

\subsection{Triangular Function}

$$
\boldsymbol{\mu}(\boldsymbol{x})=\left\{\begin{array}{cc}
0 ; & \boldsymbol{x} \leq \boldsymbol{a} \text { or } x \geq \boldsymbol{c} \\
(\boldsymbol{x}-\boldsymbol{a}) /(\boldsymbol{b}-\boldsymbol{a}) ; & \boldsymbol{a} \leq x \leq \boldsymbol{b} \\
(\boldsymbol{c}-\boldsymbol{x}) /(\boldsymbol{c}-\boldsymbol{b}) ; & \boldsymbol{b} \leq x \leq \boldsymbol{c}
\end{array}\right.
$$


Note:

a : the smallest domain value that has zero membership degrees

b : midpoint

$\mathrm{c}:$ the largest domain value that has one membership degrees

$\mathrm{x}$ : input value that will be changed into fuzzy numbers

The graph of the triangle function can be seen in Figure 2.

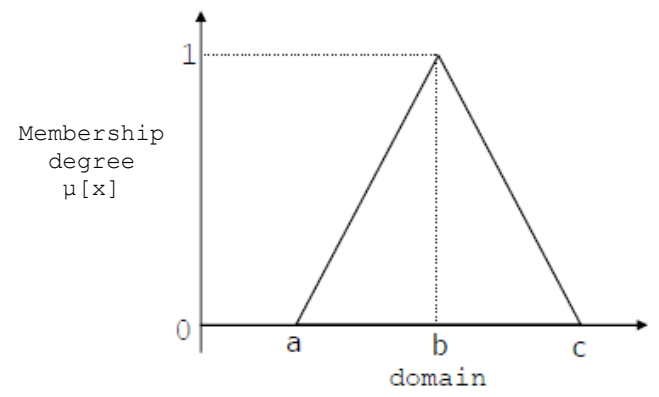

Fig. 2. Graph of Triangular Membership Functions

\subsection{Trapesium Function}

$$
\mu(x)=\left\{\begin{array}{cc}
0 ; & x \leq a \text { or } x \geq d \\
\frac{x-a}{b-a} ; & a \leq x \leq b \\
\frac{d}{d-x} ; & b \leq x \leq c \\
d-c & c \leq x \leq d
\end{array}\right.
$$

Note:

a : the smallest domain value that has zero membership degrees

b : the smallest domain value that has one membership degree

c : the largest domain value that has one membership degree

$\mathrm{d}$ : the largest domain value that has zero membership degrees

$\mathrm{x}$ : input value to be converted into fuzzy numbers

Graphs of trapezoidal functions can be seen in Figure 3. 


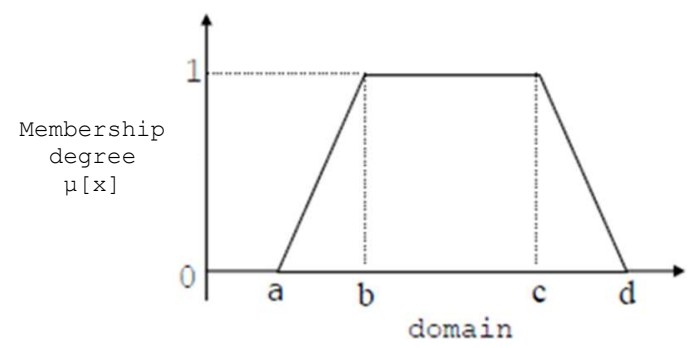

Fig. 3. Graph of Trapesium Membership Functions

Database design is needed to facilitate data storage. The database used for this application uses a data table consisting of 6 tables. The six tables are:

1. Admin Table

This table contains the username and password datafrom the admin. Disease table specification can be seen in table 1 .

Table 1. Admin Table Specification

\begin{tabular}{cccc}
\hline Fields & Data Type & Size & Description \\
\hline ID_Admin & Integer & & ID Admin \\
Name & Varchar & 50 & Admin Name \\
Username_Admin & Varchar & 30 & Username of Admin \\
Password_Admin & Varchar & 100 & Password of Admin \\
\hline
\end{tabular}

2. Table of Diseases

This table has contents about data on the names of diseases and solutions for the disease. Symptom table specification can be seen in table 2 .

Table 2. Diseases Table Specification

\begin{tabular}{cccc}
\hline Fields & Data Type & Size & Description \\
\hline ID_Diseases & Varchar & 5 & ID of the disease record \\
Diseases_Name & Varchar & 125 & Diseases name \\
Solution & Varchar & 255 & Solution for treating the disease \\
ID_Category & Integer & & Category ID \\
\hline
\end{tabular}

3. Table of Symptoms

This table contains the clinical symptoms that cause the disease. The rule table specification can be seen in table 3 . 
Table 3. Symptoms Table Specification

\begin{tabular}{|c|c|c|c|}
\hline Fields & Data Type & Size & Description \\
\hline ID_Symptoms & Varchar & 5 & ID of the symptoms record \\
\hline Symptoms_Name & Varchar & 125 & Symptoms name \\
\hline Parent_ID & Integer & & Symptoms parents ID \\
\hline Min & Float & 8 & $\begin{array}{c}\text { Minimum value of sympthom linguistic } \\
\text { variable }\end{array}$ \\
\hline Max & Float & 8 & $\begin{array}{c}\text { Maximum value of sympthom linguistic } \\
\text { variable }\end{array}$ \\
\hline Interval & Float & 8 & $\begin{array}{c}\text { Interval value of sympthom linguistic } \\
\text { variable }\end{array}$ \\
\hline ID_Category & Integer & & Category ID \\
\hline
\end{tabular}

4. Table Rule

This table rules the clinical symptoms of a disease. The medical record table specification can be seen in table 4 .

Table 4. Rule Table Specification

\begin{tabular}{cccc}
\hline Fields & Data Type & Size & Description \\
\hline ID_Rule & Integer & & ID of the rule record \\
ID_Diseases & Integer & & ID of the disease record \\
ID_Symptoms & Integer & & ID of the symptoms record \\
ID_Category & Integer & & Category ID \\
\hline
\end{tabular}

5. Medical Record Table

This table contains data on diseases and symptoms that are triggered. Table categories specification can be seen in table 5 .

Table 5. Medical Record Table Specification

\begin{tabular}{cccc}
\hline Fields & Data Type & Size & Description \\
\hline ID_MedRec & Integer & & ID of the medical record \\
ID_Diseases & Integer & & ID of the disease record \\
ID_Symptoms & Integer & \multirow{2}{*}{50} & ID of the symptoms record \\
Code & Varchar & Medical records code \\
ID_Category & Integer & & Category ID \\
\hline
\end{tabular}

6. Category table

This table is useful for making programs can input the same symptoms on the rule but with different disease categories. The table specification can be seen in table 6 . 
Table 6. Category Table Specification

\begin{tabular}{cccc}
\hline Fields & Data Type & Size & Description \\
\hline ID_Category & Integer & & Category ID \\
Category_Name & Varchar & 125 & Name of the category \\
\hline
\end{tabular}

The application of fuzzy inference system to diagnose this disease was tested using the Black Box Testing method which is a testing system to find errors in incorrect or missing functions, interface errors, errors in data structures or external database access. Black Box Testing is done repeatedly to get program output in accordance with the design that has been made before, if errors are found, the program will be repaired.

Tests of each module were done in the hope that all the functions contained in each module are working properly and the display interface and information provided does not confuse the user. This test can be declared successful if module components can be used according to their functions.

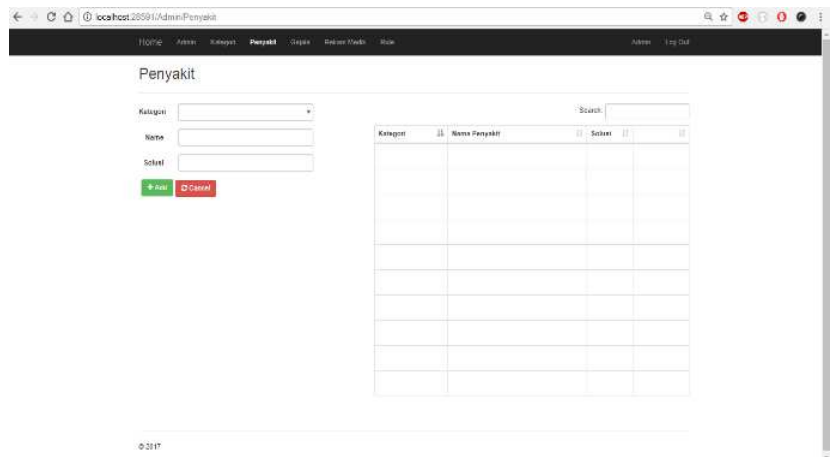

Fig. 4. Display of the Main Menu

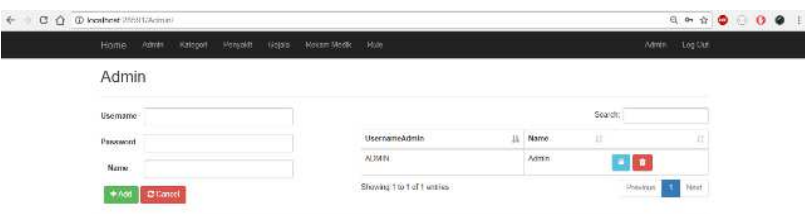$$
\text { sow }
$$

Fig. 5. Admin Module Display

Testing of the main module is going well. All menus in the main module can function properly. Buttons in this application program like admin, diagnosis, and assistance can be carried out according to its function. Likewise with the admin module, diagnosis module, the help module has also functioned well.

Admin module testing starts with the first stage, which is inputting the disease category. After that the disease data is inputted into the database along with the categories that correspond to 
the type of the disease. If you want to add data with different types of diseases, the admin must first select the category of disease and then input the new disease data with the new category. Then input the symptoms of each disease based on the category of the disease.

\section{Conclusion}

In this testing phase, it can be concluded that the functions in each module and menu in this application program are functioning according to the design that has been made.

\section{Acknowledgements}

Thanks to the Ministry of Research, Technology and Higher Education (Ristekdikti) for funding this research which is part of the research "Using Fuzzy Theory to deal with the uncertainty of symptoms of psychiatric illness in Expert Systems" through the Applied Product Grant.

\section{References}

[1] Amindoust A, Ahmed S, Saghafinia A and Bahreininejad A 2012 Sustainable supplier selection: A ranking model based on fuzzy inference system Appl. Soft Comput. J. [2] Abraham A 2005 Adaptation of Fuzzy Inference System Using Neural Learning [3] Tan J S Y and Sidhu A S 2019 Fuzzy inference system Studies in Computational Intelligence

[4] Sri Kusumadewi and Sri Hartati 2006 Neuro-Fuzzy: Integrasi Sistem Fuzzy dan Jaringan Syaraf ed 1 (Yogyakarta: Graha Ilmu) 